\title{
Adenomatoid tumor of the uterus: an incidental finding
}

\section{Abstract}

An incidental finding of adenomatoid tumor was diagnosed in a hysterectomy specimen of a postmenopausal women who underwent surgery for cervical descent. In intra - operative findings multiple small vesicular lesions were seen over the uterine serosal surface. On a detailed review of literature we found that it is predominantly a benign tumor with histiogenesis of mesothelioma. Hence, no aggressive post-operative follow-up is required in these patients.
Volume 7 Issue I - 2017

\section{Shailja Verma,' Poonam Sachdeva ${ }^{2}$ \\ 'Senior Resident OBGYN, LokNayak Hospital, India \\ ${ }^{2}$ Consultant OBGYN, LokNayak Hospital, India}

Correspondence: Shailja Verma, Flat no.257, Great India Aptt, Sector 6/I5, Dwarka, New Delhi - I 10075, India, Tel 91 98| |734| 93; +9|-0| | 25080453, Email drsvp9@gmail.com

\section{Case summary}

A 48 years, Para3 Living3 perimenopausal women with regular menstrual cycles underwent surgery for 3rd degree cervical descent and minimal cystocele and rectocele. Internal examination showed uterus of around eight weeks size, anteverted, mobile with bilateral fornices free. During her stay in hospital, all pre-operative work up done was within normal limits. Cervical smear was reported inflammatory. She had vaginal hysterectomy with anterior and posterior colpo-perineorrhaphy. Intra - operative findings showed uterus of 8 weeks size with multiple small $(1 * 1 \mathrm{~cm})$ vesicular lesions present all over serosal surface of the uterus (Figure $1 \& 2$ ).

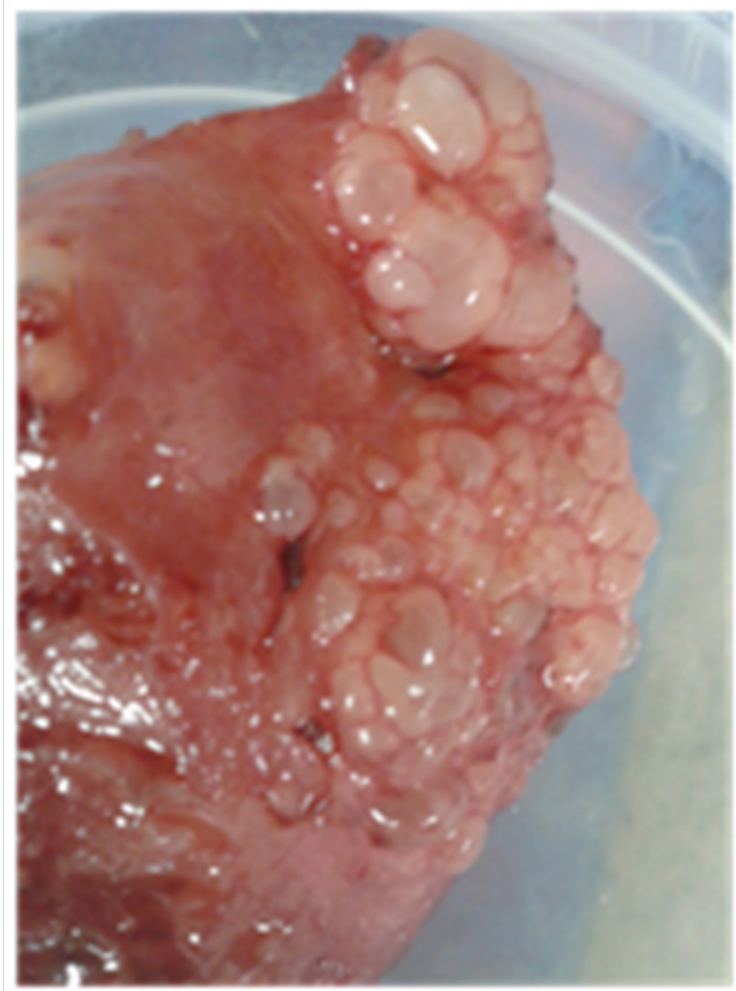

Figure I Vesicular lesions present all over serosal surface of the uterus.

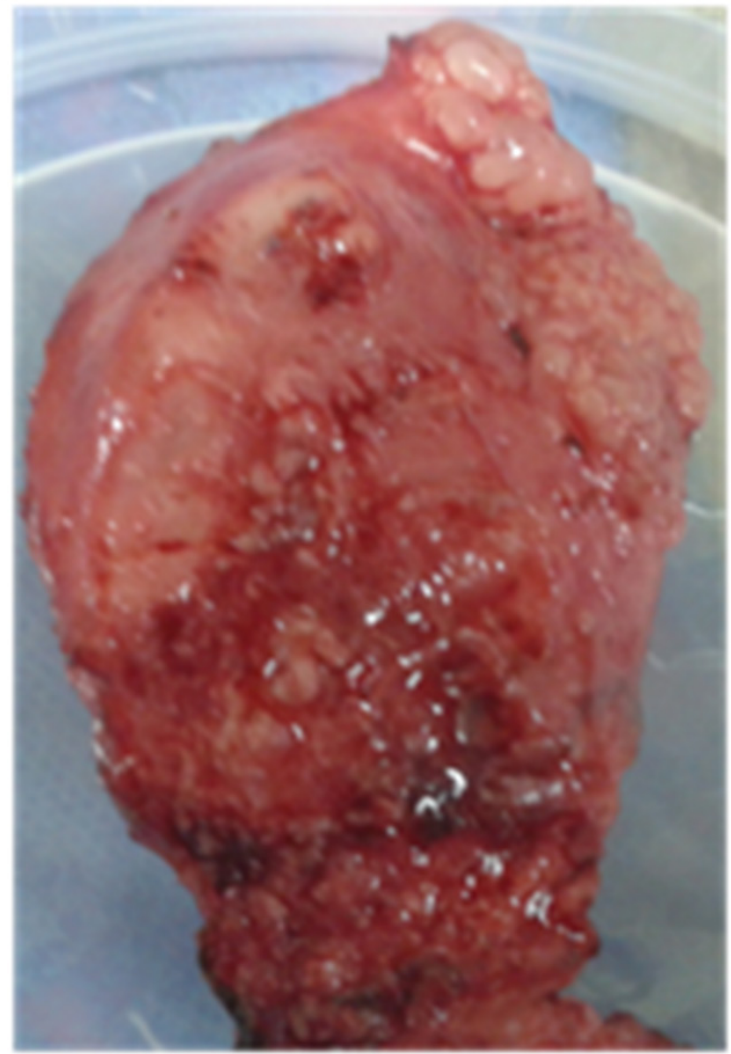

Figure 2 Vesicular lesions present all over serosal surface of the uterus.

Specimen sent for frozen section to rule out any malignant pathology, which showed cystic spaces lined by benign cuboidal to columnar epithelial cells. No cyto-architectural atypia, mitosis or necrosis noted. Bilateral fallopian tubes \& ovaries were normal. A small polyp was present in the endometrial cavity. Final histopathology report came as chronic cervicitis, adenomyosis of the uterus with proliferative endometrium. Multiple sections taken from serosal aspect of the uterus were showing features suggestive of adenomatoid tumor. She otherwise had an uneventful recovery with an early discharge. 


\section{Discussion}

The term adenomatoid tumor was first proposed by Golden and Ash in $1945 .^{1}$ They are relatively rare benign neoplasms that usually arise in the genital tract. ${ }^{2}$ The tumor is most frequently observed in male genitalia, commonly, the epididymis. ${ }^{3}$ It also appears in the female genitalia of which fallopian tubes are the most common site, followed by the uterus and ovaries. ${ }^{2}$ The posterior surface of uterus, especially in the cornua, it has more predilection. They are mostly subserosal or situated in the outermost zone of the myometrium. Histiogenesis of adenomatoid tumors is controversial; mesonephric, mullerian, endothelial and mesothelial origins have been suggested. Previous studies based on transmission electron microscopy, scanning electron microscopy and immunohistology support more of a mesothelial origin..$^{2-4}$ Hence, they are a type of benign mesotheliomas.

Incidence of adnomatoid tumors in the uterus in one series has been reported to be $1.2 \%{ }^{5}$ However, the true incidence is probably greater because these tumors frequently go unsampled as a result of their small size and gross appearance, which is similar to that of leiomyoma., Most large adenomatoid tumors are located subserosally in posterior wall of fundus or near the cornua. ${ }^{4,6}$ Most of the adenomatoid tumors of uterus are solitary, asymptomatic tumors that are incidentally discovered in hysterectomy specimens. ${ }^{7}$ Adenomatoid tumors of the uterus typically occur in women of reproductive age. The majority of lesions are solitary, small and subserosal, with a median size of $2 \mathrm{~cm}(0.5$ to $4 \mathrm{~cm})$, and usually well circumscribed. Their size is mostly within $5 \mathrm{~mm}$ of the uterine serosal surface.

Several histologic types of adenomatoid tumors are found. Quigley and Hart described four types: adenoid, angomatoid, solid and cystic.? The most frequent types are the adenoid and the angiomatoid. The cystic type is the least common type and is very rare but has been reported in the pathology literature in several case reports. $\left.{ }^{3,46}\right]$. Combinations of two or more patterns occurred in all tumors, but one major type prevails commonly.

Microscopically, they present with four distinctive histological types, immunohistochemically given positive staining for keratin and for the mesothelial marker. They are characterized by a proliferation of flattened-to polygonal cells, showing frequent vacuolization arranged in gland like cystic spaces, tubules and cords interspersed between the muscle fibres of the myometrium. Due to the frequent predominanace of smooth muscle in these tumors, the initial impression is frequently made, a variant of leiomyoma. It is doubted whether the muscle is actually a neoplastic component of the adenomatoid tumor. It is believed to be a reactive hyperplasia of indigenous myometrial smooth muscle, which encompasses the adenomatoid tumor in a fashion analogous to adenomyosis of uterus. This contention is supported by the absence of smooth muscle bundles in adenomatoid tumors occurring in sites where muscle is not normally present, like ovary and mesentry. Though the gland like spaces resemble the clear spaces seen in adipose deposits of lipoleiomyoma, but closer evaluation rules out one. Also, the absence of associated endometrial- type stroma or typical columnar endometrial epithelial cells differentiated it from adenomyoma. These tumors can mimic hemangioma or lymphangioma on histopathology, but the absence of material within the lumen, as well as the absent expression on endothelial markers like CD 34 on immunohistochemistry, will argue against this diagnosis. The immunohistochemical results support the theories of histiogenesis of the adenomatoid tumor as a type of benign mesothelioma. ${ }^{8}$

D2-40 is the most useful marker for adenomatoid tumors in the female genital tract because of its combined high sensitivity and limited background staining. ${ }^{9}$ But as this antigen is also used to identify the lining of lymphatic vessels, care must be taken not to rely on this stain completely to differentiate the two. ${ }^{10}$ These tumor cells are strongly positive for cytokeratin, vimentin, calretinin and HMBE-1 (anti-human mesothelioma antibody), but do not express EMA, CEA. ${ }^{1,11,12}$ One study found estrogen and progesterone receptor expression is weak and focal and none stained for the androgen receptor. ${ }^{13}$

Most significantly, the differential diagnosis for adenomatoid tumor may also include infiltrating carcinoma. Cytologic features of the lesion, particularly lack of significant nuclear atypia or mitotic activity and identification of typical features as described above should assist in the recognition of this lesion. Also, Calretinin, which is strongly expressed in adenomatoid tumor, is not expressed in most of the carcinomas which might involve the myometrium, although it must be remembered that it can be expressed in certain ovarian tumors, in which case additional stains may be required if the histology features are not clear cut. ${ }^{10,14,15}$ Adenomatoid tumors with a diffuse infiltrative growth pattern have to be distinguished from malignant lesions such as metastatic signet ring cell adenocarcinoma, epithelioid hemangioendothelioma, along with germ cell tumor or sex cord stromal tumors as told above. ${ }^{11}$ But unlike malignancy they do not require aggressive follow up.

Adenomatoid tumors may arise from inclusions of mesothelioma incorporated into subserosal connective tissue or myometrium. Patients who develop adenomatoid tumors may have a labile peritoneum with a propensity to form a variety of proliferative lesions of mesothelial cells. Some adenomatoid tumors conceivably could arise directly from uterine mesenchymal cells, which have retained a potential to differentiate into mesothelial cells. ${ }^{16}$

This tumor though benign still its incidental occurrence keeps gynecologists inquisitive till histopathology confirmation.

\section{Acknowledgments}

None.

\section{Conflicts of interest}

None.

\section{References}

1. Hong R, Choi DY, Choi SJ, et al. Multicentric infarcted leiomyoadenomatoid tumor: a case report. Int J Clin Exo Pathol. 2009;2(1):99-103.

2. Mitsumori A, Morimoto M, Matsubara S, et al. MR appearance of adenomatoid tumor of the uterus. J Comput Assist Tomogr. 2000;24(4):610-613.

3. Livingston EG, Guis MS, Pearl ML, et al. Diffuse atenomatoid tumor of the uterus with a serosal papillary cystic component. Int J Gynecol Pathol. 1992;11(4):288-292.

4. Rosa GD, Boscaino A, Terracciano LM, et al. Giant adenomatoid tumors of the uterus. Int J Gynecol Pathol. 1992;11(2):156-160.

5. Tiltman AJ. Adenomatoid tumors of the uterus. Histopathology. $1980 ; 4: 437-43$

6. Palacios J, Manrique AS, Villaespesa AR, et al. Cystic adenomatoid tumor of the uterus. Int $J$ Gynecol Pathol. 1991;10(3):296301 
7. Quigley JC, Hart WR. Adenomatoid tumor of the uterus. Am J Clin Pathol. 1981;76:627-635.

8. Buzzia A, Pezzica E, Crescini C. An Adenomatoid tumor of the uterus. Minerva Ginecol. 1994;46(6):359-364.

9. Ankur R Sangoi, Jesse K McKenny, Erich J Schwartz, et al. Adeomatoid tumors of the female and male genital tracts: a clinicopathological and immunohistochemical study of 4 cases. Modern Pathology. 2009;22(9):1228-1235.

10. Alkatout I, Bojahr B, Dittmann L, et al. Precarious preoperative diagnostics and hints for the laparoscopic excision of uterine adenomatoid tumors: two exemplary cases and literature review. Fert Ster. 2011;95(3):1119e5-1119e8.

11. Bolat F, Kocer E, Bal N, et al. Adenomatoid tumor of the female genital tract: Report of three cases. Turk J Pathol. 2007;23(2):98-102.

12. Amre R, Constantino J, Lu S, et al. Pathologic quiz case: a 52 year old woman with a uterine mass. Leiomyo-adenomatoid tumor of the uterus. Arch Pathol Lab Med. 2005;129(3):e77-e78.

13. Wachter DL, Wunch PH, Hartmann A, et al. Adenomatoid tumors of the female and male genital tract. A Comparitive clinicopatholica and immunohistochemical analysis of 47 cases emphasizing their site specific morphologic diversity. Virchows Arch. 2011; 458(5): 593-602.

14. Amérigo J, Amérigo-Góngora M, Giménez-Pizarro A, et al. Leiomyoadenomatoid tumor of the uterus: a distinct morphological entity? Arch Gynecol Obstet. 2010; 282(4):451-454.

15. Erra S, Pastormerlo M, Gregori G, A case of leiomyoadenomatoid tumor of the uterine serosa: speculations about differential diagnosis. BMJ Case Rep. 2009
16. Mazur MT, Kraus FT) Histiogenesis of morphologic variations in tumors of the uterine wall. Am J Surg Pathol. 1980;4(1):59-74.

17. Wachter DL, Wunch PH, Hartmann A, Adenomatoid tumors of the female and male genital tract. A Comparitive clinicopatholica and immunohistochemical analysis of 47 cases emphasizing their site specific morphologic diversity. Virchows Arch. 2011;458(5):593-602.

18. Alkatout I, Bojahr B, Dittmann L, Warneke V, et al. Precarious preoperative diagnostics and hints for the laparoscopic excision of uterine adenomatoid tumors: two exemplary cases and literature review. Fert Ster. 2011;95(3):1119e5-1119e8.

19. Amérigo J, Amérigo-Góngora M, Giménez-Pizarro A, et al. Leiomyoadenomatoid tumor of the uterus: a distinct morphological entity? Arch Gynecol Obstet. 2010;282(4):451-454.

20. Erra S, Pastormerlo M, Gregori G, A case of leiomyoadenomatoid tumor of the uterine serosa: speculations about differential diagnosis. $B M J$ Case Rep. 2009

21. Bolat F, Kocer E, Bal N, Adenomatoid tumor of the female genital tract: Report of three cases. Turk J Pathol. 2007;23(2):98-102.

22. Amre R, Constantino J, Lu S, et al. Pathologic quiz case: a 52 year old woman with a uterine mass. Leiomyo-adenomatoid tumor of the uterus. Arch Pathol Lab Med. 2005;129(3): e77-e78.

23. Mazur MT, Kraus FT. Histiogenesis of morphologic variations in tumors of the uterine wall. Am J Surg Pathol. 1980;4(1):59-74. 